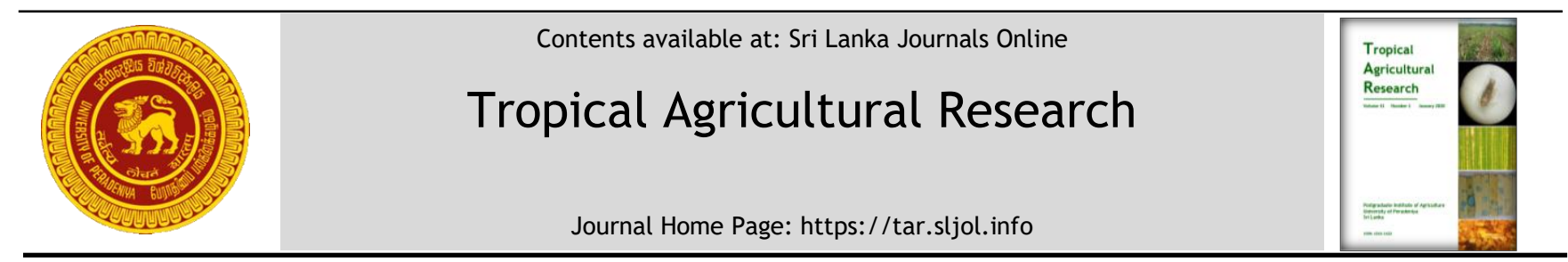

\title{
Morphometric and Molecular Characterization of Isolates of the Root Lesion Nematode, Pratylenchus loosi Infecting Tea in Sri Lanka
}

\author{
P. G. D. S. Amarasena1*, K. M. Mohotti1 ${ }^{1}$ D. M. De Costa ${ }^{2}$ and J. Fosu-Nyarko ${ }^{3}$ \\ ${ }^{1}$ Tea Research Institute of Sri Lanka, Talawakelle, Sri Lanka \\ 2 Department of Agricultural Biology, Faculty of Agriculture, University of Peradeniya, Peradeniya, Sri Lanka \\ ${ }_{3}^{3}$ State Agricultural Biotechnology Centre, College of Science, Health, Engineering and Education, Murdoch University, \\ Perth, Australia
}

\section{ARTICLE INFO}

\section{Article history:}

Received: 20 July 2019

Accepted: 12 October 2019

Available online: 1 December 2019

\section{Keywords:}

D2/D3 expansion segments of the 28-

rDNA gene

ITS region

Molecular characterization

Morphometry

Pratylenchus loosi

\section{Citation:}

Amarasena, P. G. D. S., Mohotti, K. M., De Costa, D. M. and Fosu-Nyarko, J. (2020)

Morphometric and Molecular

Characterization of Isolates of the Root

Lesion Nematode, Pratylenchus loosi

Infecting Tea in Sri Lanka. Tropical

Agricultural Research, 31(1): 57-71.

DOI: http://doi.org/10.4038/tar.v31i1.8344

Amarasena, P. G. D. S.

https://orcid.org/0000-0001-5221-3348

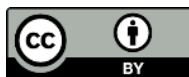

\begin{abstract}
The Root-lesion nematode, Pratylenchus loosi Loof inhabits all tea growing regions of Sri Lanka depicting a variety of symptoms and damage severities to affected tea. Though much has been researched on biology and control measures, isolate characterization has not been attempted. Hence, male and female morphometric variations and molecular characterization of $P$. loosi populations isolated from different agro-ecological regions in Sri Lanka viz. PL1 (Cecilton, Balangoda), PL2 (Delmar, Halgranoya), PL3 (Hapugastenna, Ratnapura) PL4 (Mahadowa, Passara), PL5 (Nawalapitiya) and PL6 (Richiland, Deniyaya) were studied. Female morphometrics of $P$. loosi showed intraspecific variation and clustered in four groups in Principal Component Analysis where PL1 and PL5 were closely-related while PL3 and PL6 clustered separately with the exception of PL2 and PL4. Sequence analysis of the D2/D3 expansion segments of the 28S rDNA gene of the $P$. loosi populations revealed that PL3 and PL6 were closelyrelated while PL1, PL4 and PL5 were relatively distant. Sequences of the ITS region of rDNA placed PL3 and PL6 in a single clade. The isolates PL1, PL2, PL4 and PL5 were relatively distantly-related and PL2 and PL4 were relatively distant from the other populations. Molecular characterization further validated the relatedness of PL1 and PL5, PL3 and PL6 and, PL2 and PL4 obtained from the morphometric data. The divergence in P. loosi populations shown in this study supports evidence of intra specific isolates resulting different symptomological expressions and thus implies need of specific management strategies in managing nematode infestations in tea plantations in Sri Lanka.
\end{abstract}

*Corresponding Author: deepthiamarasena@yahoo.com 


\section{INTRODUCTION}

Tea, [Camellia sinensis (L) O. Kunze (Theaceae)], is the major plantation crop grown in Sri Lanka. Plant parasitic nematodes are considered one of the key pests limiting establishment, growth and productivity of tea. Pratylenchus loosi is the most predominant nematode species causing economic damage to tea cultivation in different agro climatic regions in Sri Lanka (Gnanapragasam and Mohotti, 2005). Mohotti (1998 and 2002) indicated that there may be several $P$. loosi isolates after studying populations of the nematodes from Sri Lanka, Japan, Iran and Florida. Mizukubo (1998) introduced the $P$. loosi species complex which appears to include phylogenetically distinct isolates based on four Japanese isolates and a Sri Lankan isolate. However, possible intraspecific variations of different populations present in different localities in Sri Lanka have not been studied.

In the past decades, several molecular tools have been deployed to identify and compare nematodes, at the species level and between populations of the same species. For species of the genus Pratylenchus, a remarkable difference exists in the sizes of the ITS region of rRNA of the nematodes; so far, the difference between the smallest and the largest amplified ITS regions is about 350 bases (Castillo and Vovlas, 2007). In addition, intraspecific variation in the ITS region has been observed in this genus, particularly within populations of Pratylenchus coffeae and Pratylenchus vulnus (Orui, 1996; Uehara et al., 1998; Waeyenberge et al., 2000; Mizukubo et al., 2003, Begum et al., 2019). Sequences of the D2/D3 expansion segment of the 28S rDNA gene has also been used to distinguish between Pratylenchus spp and, has been shown to be an important and strong molecular tool for nematode diagnostics (Handoo et al., 2001; Subbotin et al., 2006; de la Pena et al., 2007).

This study was, therefore, undertaken with the objective of using morphometrics and molecular data to characterize $P$. loosi populations collected from six geographic locations in Sri Lanka causing varying symptomolgical expressions and damage to tea.

\section{MATERIALS AND METHODS}

\section{Selection of sampling sites}

Sampling sites to collect P. loosi populations to study the morphometrics and molecular data were selected by reviewing history of records maintained by the Nematology Laboratory of the Tea Research Institute, Sri Lanka. Accordingly, six locations representing different elevations with higher P. loosi populations were recognized and sampled in this study (Table 1).

Table 1: Details of the sampling sites

\begin{tabular}{llcccc}
\hline $\begin{array}{l}\text { Code } \\
\text { No. }\end{array}$ & \multicolumn{1}{c}{ Location } & Latitude & Altitude & AER & $\begin{array}{c}\text { Elevation } \\
\text { (m amsl) }\end{array}$ \\
\hline PL1 & Cecilton Estate, Balangoda & $6^{\circ} 43^{\prime} 60^{\prime \prime} \mathrm{N}$ & $80^{\circ} 39^{\prime} 0^{\prime \prime} \mathrm{E}$ & IM2b & 780 \\
PL2 & Delmar Estate, Ragala & $7^{\circ} 0^{\prime} 0^{\prime \prime} \mathrm{N}$ & $80^{\circ} 52^{\prime} 0^{\prime \prime} \mathrm{E}$ & $\mathrm{IU} 2$ & 1400 \\
PL3 & Hapugastenna Estate, Ratnapuara & $6^{\circ} 69^{\prime} 3^{\prime \prime} \mathrm{N}$ & $80^{\circ} 38^{\prime} 6^{\prime \prime} \mathrm{E}$ & $\mathrm{WM} 1 \mathrm{a}$ & 810 \\
PL4 & Mahadowa Estate, Passara & $7^{\circ} 0^{\prime} 0^{\prime \prime} \mathrm{N}$ & $81^{\circ} 10^{\prime} 0^{\prime \prime} \mathrm{E}$ & $\mathrm{IU} 3 \mathrm{c}$ & 1280 \\
PL5 & Nawalapitiya (Small holder land) & $7^{\circ} 3^{\prime} 0^{\prime \prime} \mathrm{N}$ & $80^{\circ} 32^{\prime} 0^{\prime \prime} \mathrm{E}$ & WM2a & 550 \\
PL6 & Richiland Estate, Deniyaya & $6^{\circ} 19^{\prime} 28^{\prime \prime} \mathrm{N}$ & $80^{\circ} 33^{\prime} 43^{\prime \prime} \mathrm{E}$ & WM1a & 470 \\
\hline
\end{tabular}




\section{Morphometric characterization of $\boldsymbol{P}$. Loosi populations}

The $P$. loosi specimens were collected from the sampling sites described in Table 1 and the slides were prepared as per the standard protocols in Seinhorst (1959). For the study, 20 female and 12 male specimens of $P$. loosi were used for each site. Specimens were observed under OPTIKA B 500 microscope, and all morphometric measurements were done with Optika Vision Pro plus (Version 2.7) software. The measurements taken were as follows;

\section{Female}

Body length (L), Maximum body width (w), Body width at anus, Tail length, Head end vulva, Head end - anus, Anus - phasmid, Phasmid - tail end, Stylet length, Stylet base DOGO, Body length / maximum body width, Body length / maximum body width, Body length / tail length, Tail length / body width at anus, Tail length / body width at anus, Distance to vulva to anterior end/ Body length * $100 \%$ (V (\%)), Head end - vulva/ head end - anus* $100 \% \mathrm{~V}^{\prime}(\%)$.

\section{Male}

Body length (L), Maximum body width (w), Tail length, Stylet length, Spicule, Body length / maximum body width, Body length / maximum body width, Body length / tail length, Volume $\left(\mu \mathrm{m}^{3}\right)$ and weight $(\mu \mathrm{g})$.

De Man's formula for male and female morphometrics were calculated based on Siddiqi (1986).

\section{Data analysis}

The data were statistically analysed using SAS 9.1. Principle Component Analysis was used to make an objective assessment of the relative similarity among the populations using fourteen (14) morphometric characters for the females.
Molecular characterization of $P$. loosi populations

The P. loosi populations used for molecular study were collected from the locations described in Table 1. The molecular work (e.g. PCRs, cloning, sequencing, sequence analyses and DNA homology work) of this study was carried out at the State Agricultural Biotechnology Centre (SABC), Murdoch University, Perth, Australia.

DNA extraction from single nematodes was done using phenol chloroform method and methods described by Marek et al. (2014) and Wayenberg et al. (2000).

\section{PCR of the D2/D3 rDNA}

Genomic DNA of single adult $P$. loosi nematodes were used for PCRs. Primers D2-1 (5'-GACCCGTCTTGAAACACGGA-3') and D3-2 (5'-CGGAAGGAACCAGCTACTA-3') were used for amplification of the D2/D3 expansion region of the 28S RNA gene. All PCRs were made up to $20 \mu \mathrm{l}$ with nuclease-free water and contained $10.0 \mu \mathrm{l}$ Go Taq Green master mix (Promega Corp, Australia), $1.0 \mu \mathrm{l}$ each of the primers D2-1 and D3-2 and $2.0 \mu \mathrm{l}$ of DNA template. Thermal cycling was done using an initial denaturation at $95{ }^{\circ} \mathrm{C}$ for $5 \mathrm{~min}$, followed by 50 amplification cycles (denaturation at $95^{\circ} \mathrm{C}$ for $1 \mathrm{~min}$, annealing at $55{ }^{\circ} \mathrm{C}$ for $1 \mathrm{~min}$ and extension at $72{ }^{\circ} \mathrm{C}$ for 1 min) and a final step at $72{ }^{\circ} \mathrm{C}$ for $10 \mathrm{~min}$. Amplified products were observed on $1 \%$ TAE-buffered agarose gels, stained with $\mathrm{SyBr}$ Safe DNA gel stain (Invitrogen, USA) and visualized with a Trans illuminator. PCR products were purified using the Wizard SV Gel and PCR Clean-Up System (Promega, USA) according to the manufacturer's protocol.

\section{PCR of the ITS region}

The partial 18S-ITS1-5.8S-ITS2-partial 28S of the rDNA was amplified from genomic DNA of single adult $\mathrm{P}$. loosi nematodes using the 
primer pair 26S (5'TCCTCCGCTAAATGATATGC-3' and 18S (5'GTAACAAGGTAGCTGTAGG-3'). The PCR conditions and the thermal cycling profiles were the same as those used for amplification of the D2/D3 rDNA PCR above.

Ligation of the purified PCR products to the pGEM-T cloning vector and transformation of E. coli JM109 with the ligated products were as per the manufacturer's protocol (Promega Corp). This was followed by confirmation of successful ligation by PCR of the colonies, isolation of plasmid DNA, restriction digestion of recombinant plasmids, and sequencing of plasmid DNA using standard molecular biology protocols (Sambrook et al., 1989).

\section{Sequence alignments and analyses}

The software, Finch TV 1.4.0 (Geospiza) was used to visualize and edit erroneous sequences. Clustal omega and MEGA 7.0.26 (Kumar et al., 2016) were used to align the edited sequences and to develop phylogenetic trees respectively.

\section{Phylogenetic analyses}

Phylogenetic trees were constructed using sequences of the D2/D3 28S rDNA expansion segment and ITS region separately using the Neighbour-Joining and Maximum Parsimony (MP) algorithms. Bootstrap analyses with 1000 replicates were performed to assess the degree of support for each clade on the trees. Sequences of similar regions of the respective rDNA for P. coffeae (GenBank Accession numbers HQ688681.1 and KF974721.1) were used as out-group taxon for the phylogenetic analyses.

\section{RESULTS AND DISCUSSION \\ Morphometric characterization of $P$. loosi populations}

The specimens of males and females conformed closely to the earlier descriptions of $P$. loosi, but there were noteworthy variations (Tables 2 and 3).

\section{Female populations of $\boldsymbol{P}$. loosi}

Table 2 presents the data compared with morphometrics reported earlier for P. loosi. The data showed that the measurements of the populations studied were in the ranges of previously reported $P$. loosi and confirmed their taxonomic identity. Although some may be significant, the deviations in the morphometric characters among the populations were acceptable for Pratylenchus species.

The least variable characters were considered in the comparison of different $P$. loosi populations. The results of this study showed evidence of existence of a significant intraspecific variation in the morphometric characters of $P$. loosi found in Sri Lanka.

\section{Body length (L)}

The results showed that ' $\mathrm{L}$ ' of the study population PL 4 is significantly higher $(552 \mu \mathrm{m})$ than that of the other populations. However, the mean ' $L$ ' of each of the populations and for all the populations were in the range of body lengths reported by Loof (1960), Duncan et al. (1999), Inserra et al. (2001) and Wu et al. (2002). Also, the average body length of the populations was similar to that reported for $P$. loosi identified from pasture grasses in central Florida (Inserra et al. 1996).

\section{Distance from vulva to anterior end/ body} Length * $100 \%$ - (V\%)

The distance from the vulva to the anterior end/Body Length * $100 \%(\mathrm{~V} \%)$ is the one of the most important morphometric parameters used for characterizing Pratylenchus species. Several studies have demonstrated that $\mathrm{V}$ ratio is less modified by biotic or abiotic factors and the ratio is a reliable diagnostic character for the genus. 
This was confirmed in our study which indicated a very small coefficient of variation $(2.96 \%)$ as presented in Table 2. The PL 4 population had a lower $\mathrm{V}$ ratio $(77.05 \%)$ while the PL 3 population had a significantly higher $V$ ratio $(84.01 \%)$ than the other populations.

\section{Maximum body width}

The populations from the PL 2, PL 3, PL 5 and PL 6 locations had a higher maximum body widths compared to $P$. loosi previously identified by Mohotti (1998) from several locations in Sri Lanka. In contrast, PL 4 population were on average $3 \mu \mathrm{m}$ thinner.

\section{Stylet length}

Roman and Hirschmann (1969) and Loof (1991) explained that the appearance of the stylet knobs may change during storage or after mounting in glycerine implying the diagnostic value of this character may not always be reliable. For this reason, detailed work on stylet morphology was not carried out.

However, in our study, the average stylet length of all the populations showed low coefficient of variation $(6.53 \%)$, ranging from 13.47 to $16.48 \mu \mathrm{m}$. The data showed that stylet length of all the study populations were in the range of that reported by Loof (1960) and Seinhorst (1977) of $P$. loosi identified. The PL 3 and PL 4 populations had comparatively longer stylet lengths than those of PL 2 and PL 5.

Our study showed that some morphometric features, such as the stylet length and V ratio, were less modified by biotic or abiotic factors and are probably more reliable as diagnostic characters for the Pratylenchus genus.

\section{Male populations of $P$. loosi}

Males were abundant in all the populations studied. Coefficients of variation of all the male characters showed similar trends as in the female characters. Variation in volume and weight were however less in the males of the same population. The data from this study and comparison with existing references are presented in Table 3.

\section{Tail length}

The tail length of the males of the populations studied was shorter than those to described by Mohotti (1998) except for the populations from PL 4 and PL 5. Similarly, the tail lengths of males from all the locations studied were shorter than in isolates from Taiwan (Wu et al. 2002).

\section{Body length (L)}

The ' $L$ ' of the PL 4 populations showed similar trends as in the females with highest ' $\mathrm{L}$ ' of $436.50 \mu \mathrm{m}$. Also, the male ' $\mathrm{L}$ ' was statistically not significantly different among the populations $(\mathrm{P} \leq 0.05)$. However, the mean values fall within the range in Sri Lankan populations of $P$. loosi previously described by Mohotti (1998) and generally did not conform to the findings of Handoo and Golden (1989) and Wu et al. (2002).

\section{Maximum body width}

Our data revealed that the maximum body width was highest in the PL 4 nematodes $(12.83 \mu \mathrm{m})$ and lowest in PL 6 nematodes $(12.16 \mu \mathrm{m})$. The average maximum body width of the nematodes of the six populations were in the range of those described by Mohotti (1998) but not for those described by $\mathrm{Wu}$ et al. (2002). For descriptive determination of the $P$. loosi isolates, morphometry of the female specimens was used (Figure 1).

\section{Principal component analysis}

Fourteen (14) morphometric characters of the female nematodes were used for Principal Component Analysis. The six populations were clearly separated into four groups. The PL 4, Mahadowa population and the PL 2, Delmar populations were in separate groups compared to the other populations. The PL 1 and PL 5 were clustered into one group while PL 3 and PL 6 clustered into another. 


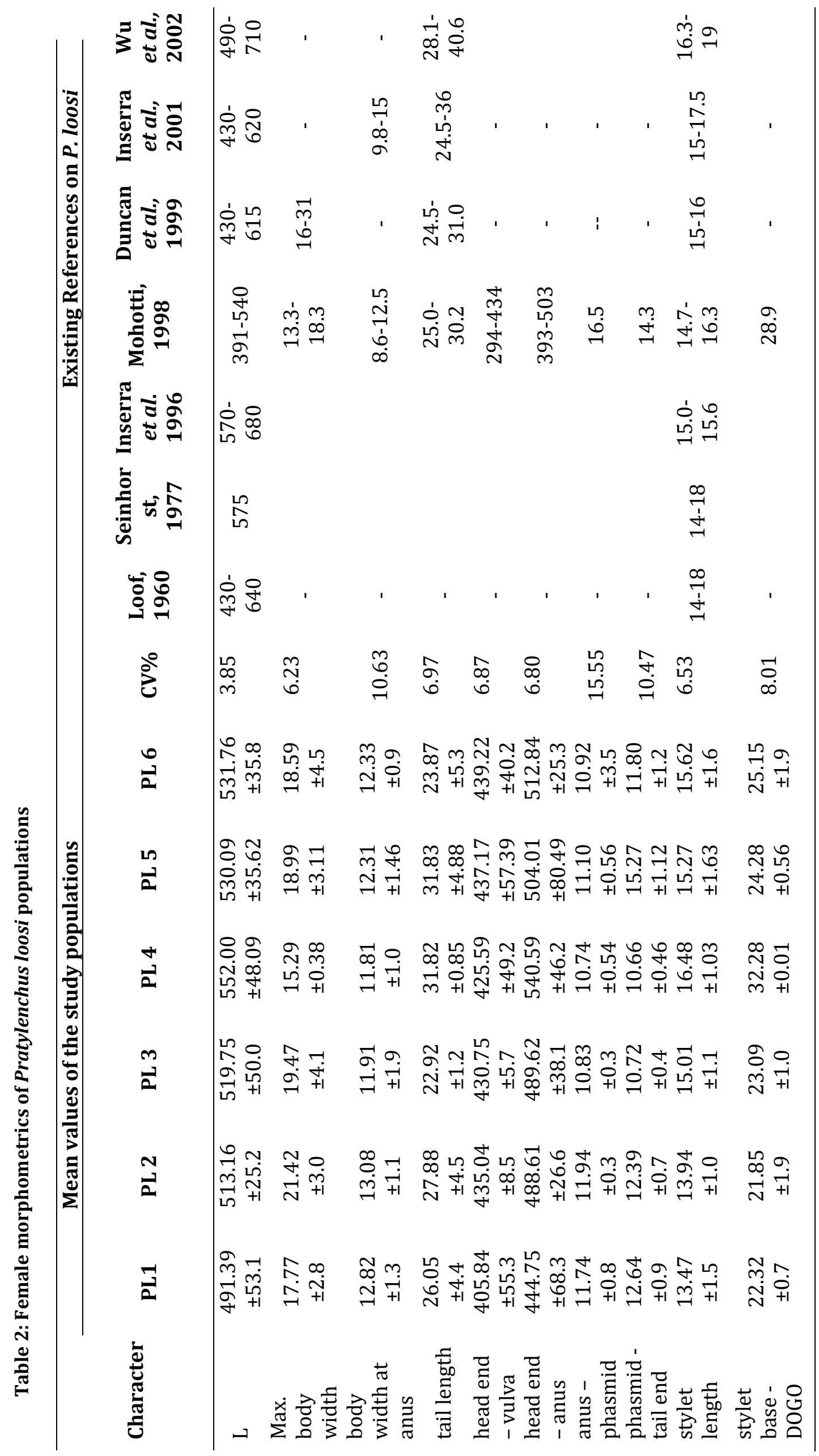




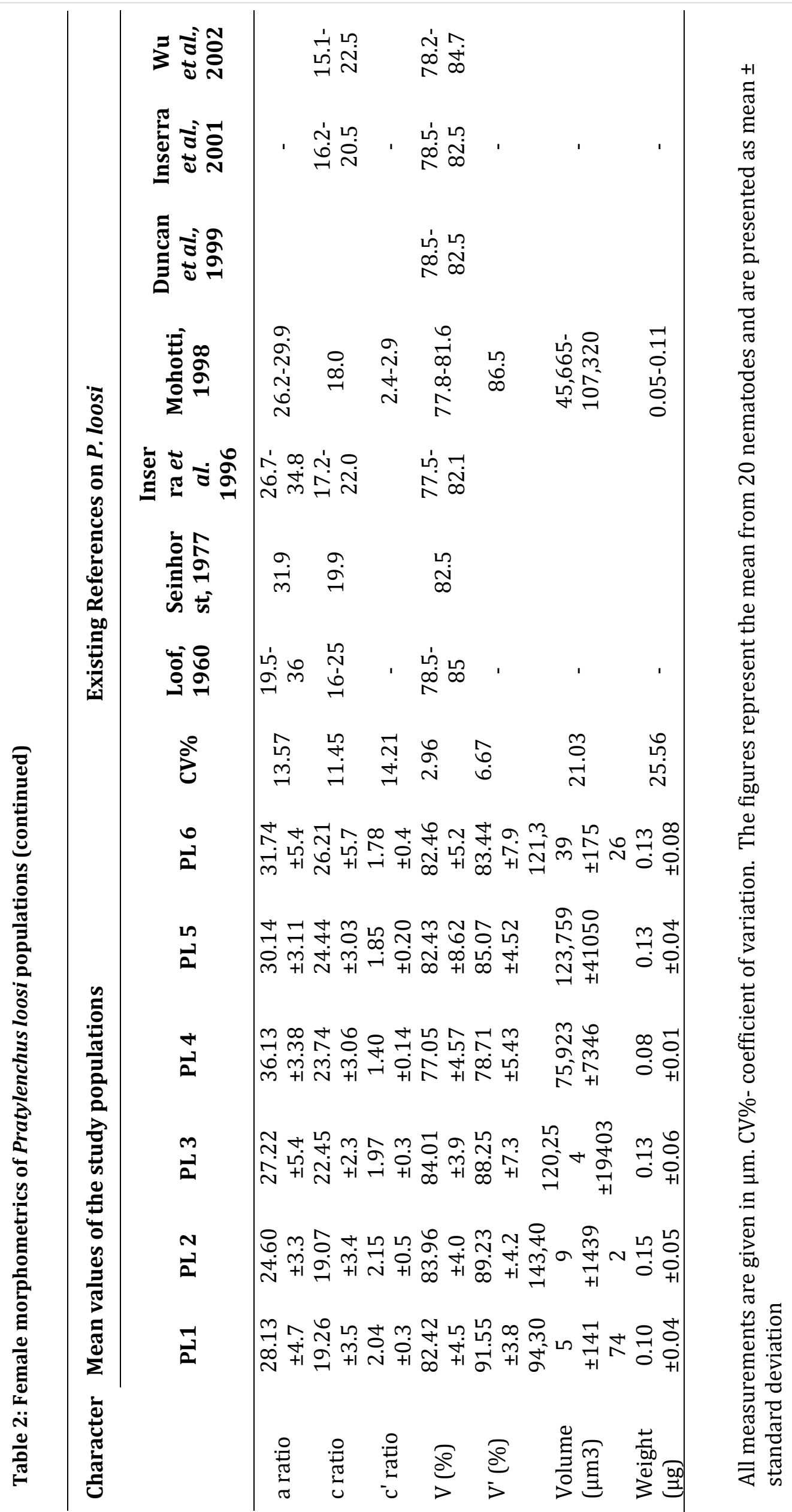




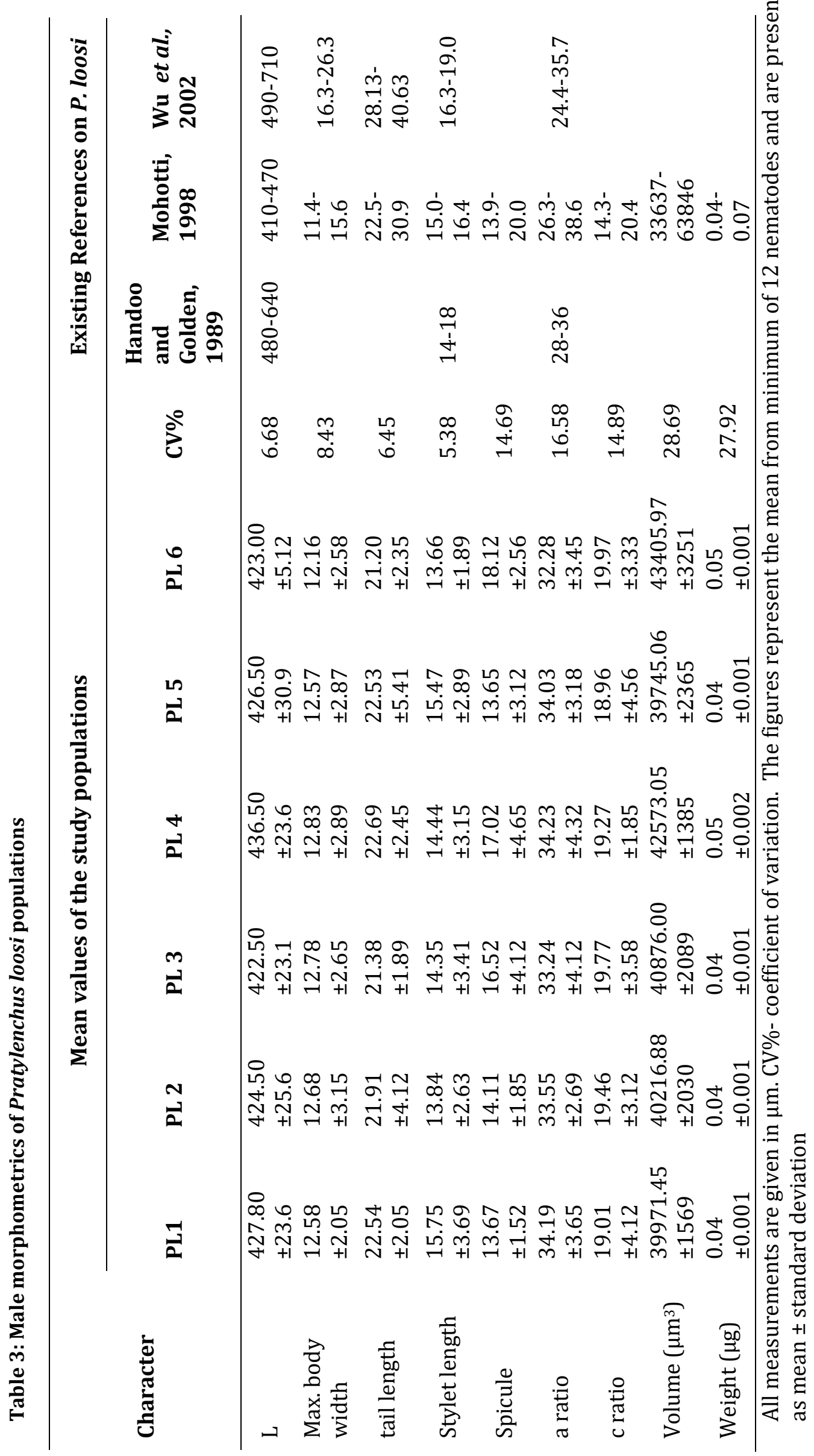




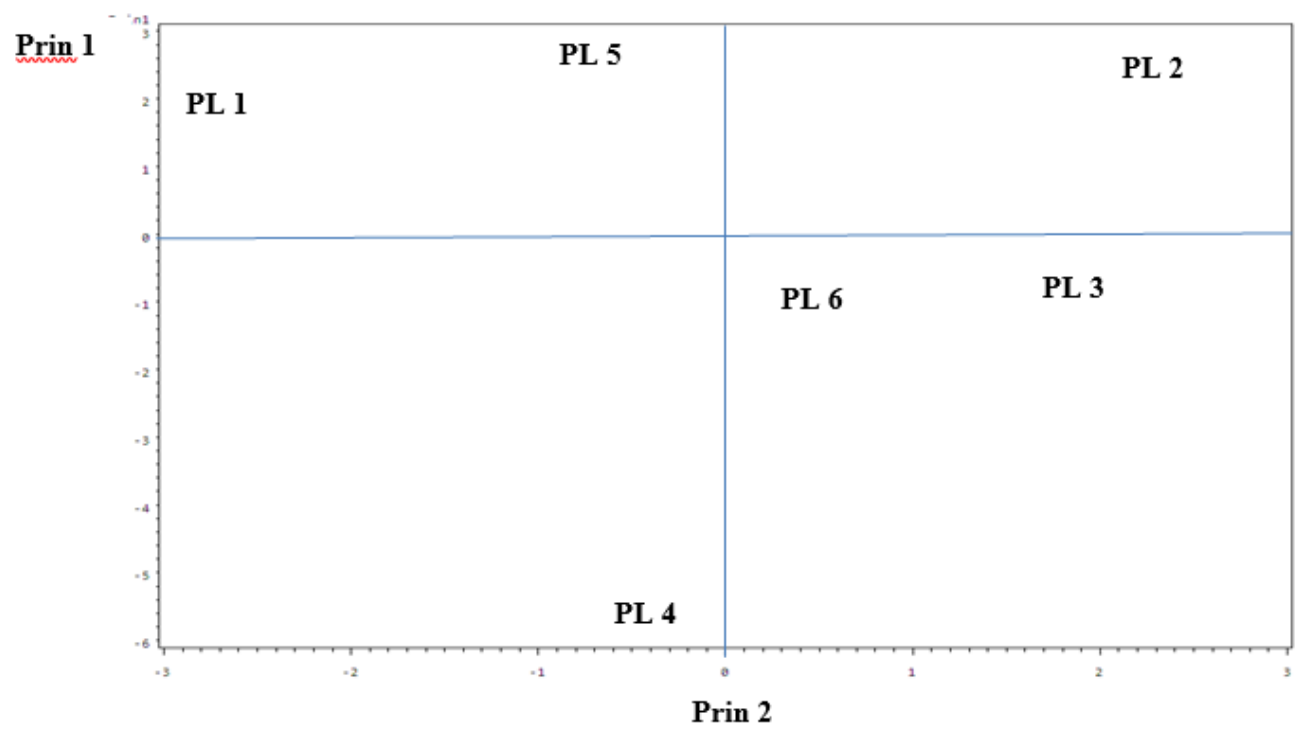

Figure 1: Principal Component Analysis of the fourteen female morphometric characters of $P$. loosi populations of PL 1-PL6

In summary, the female morphometrics of the six populations of $P$. loosi measured in this study indicates there is intraspecific variation in the nematodes (Table 2 and Figure 1). However, the PCA results did not clearly separate the populations into clusters based on their geographic locations. Generally, the specimens could be confirmed as $P$. loosi species as their morphometric features were well within the ranges of typical measurements reported for this species. The slight variations in the morphometric parameters allowed the six populations to be clustered into four distinct groups. The results revealed that PL 1 and PL 5 populations are closely-related, as were the PL 3 and PL 6 populations. However, the separation of PL 2 and PL 4 populations into individual separate groups indicate they may be morphometrically different from the other four populations.

\section{Molecular characterization of $P$. loosi populations PCR of D2/D3 rDNA}

The amplification of the D2/D3 Large Sub Unit of rDNA expansion segments yielded 345 bp fragments for all the isolates except for nematodes from PL 2 where there was no amplification.

Results of the homology search with available DNA databases of $P$. loosi species are given in Table 5. Representative sequences from all the locations best matched with P. loosi with sequence identities ranging from $96 \%$ $100 \%$. The individual sequences from each location showed some intra-species variation depicting potential isolates of $P$. loosi.

\section{Phylogenetic analysis of D2/D3 sequences}

The Neighbor-Joining trees constructed using the sequences of D2/D3 28S rDNA expansion segment are shown in Figure 2.

The five populations were clustered into different phylogenetic clades with nematodes from populations PL 6 and PL 3 closelyrelated to each other than the others. Sequences of the nematodes of the PL 3 and PL 6 populations were grouped with EF446995.1, a sequence of $P$. loosi isolated from Iran but were more distantly-related to AF170439.1 P. loosi isolate $\mathrm{T}$ which was described as a Sri Lankan isolate. The rest of the populations existed as well separated 
clusters, indicating the distant relationship they may have with PL3 and PL6 populations. The sequence divergence of the nematodes of the different populations were low based on the pairwise mean distances between sequences of the D2/D3 28S rDNA expansion segments. The best matching sequences on
Genbank are presented in Table 5. The sequences from the same location were in the same clade confirming there were no sequence differences among $P$. loosi isolates from the same location; sequences with the same number PL designation (e.g. PL5.1 and PL5.2) were from the same location.

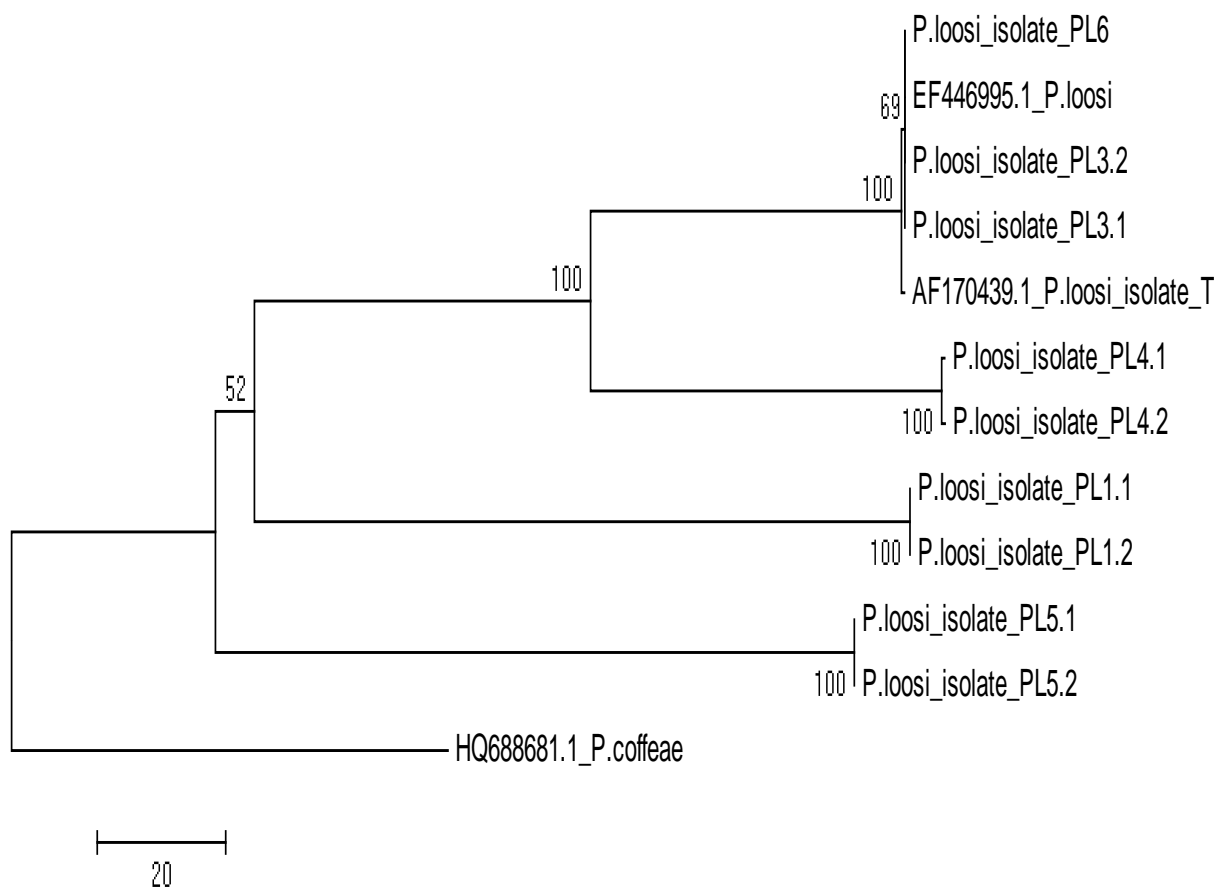

Figure 2: Neighbor joining tree of $P$. loosi populations studied, other Pratylenchus populations obtained from GenBank based on the sequence alignment of the D2/D3 28S rDNA expansion segments

\section{PCR of ITS Region}

ITS sequences of nematodes analysed showed a $100 \%$ homology and $100 \%$ query coverage with $P$. loosi 18s rRNA sequences deposited in the GenBank Database and confirmed the identity of the six populations studied (Table 4).

Based on the phylogenetic trees (Figures 3 and 4) constructed using the Maximum Parsimony and Neighbor-Joining methods, the PL 3 and PL 6 populations clustered together and formed a single clade. Nematodes of the PL4 population clustered separately but showed a genetic relationship closer to the PL 3 and PL 6 populations. The PL 2 nematodes clustered separately but showed a closer relationship to PL 4 and PL 3 and PL 6 populations than those of the PL1 and PL 5 populations. Both analyses methods showed that PL 1 and PL 5 clustered together and formed a clade with FJ712946.1 P. loosi isolate. Therefore, the results clearly indicated there is some level of intra-species variation in the $P$. loosi isolates obtained from the different locations in Sri Lanka. 
Table 4: Details of the homology search of the rDNA sequences

\begin{tabular}{llcccc}
$\begin{array}{l}\text { Sample } \\
\text { Name }\end{array}$ & \multicolumn{1}{c}{$\begin{array}{c}\text { Description of the highest } \\
\text { homologue }\end{array}$} & $\begin{array}{c}\text { Query } \\
\text { cover }\end{array}$ & E value & Identity & Accession \\
\hline PL1 & $\begin{array}{l}\text { Pratylenchus loosi isolate Jan-1 28S } \\
\text { ribosomal RNA gene, partial sequence }\end{array}$ & $100 \%$ & $3 \mathrm{e}-171$ & $99 \%$ & KF430797.1 \\
PL3 & $\begin{array}{l}\text { Pratylenchus loosi isolate EX11 28S } \\
\text { ribosomal RNA gene, partial sequence }\end{array}$ & $100 \%$ & 0.0 & $100 \%$ & KY424292.1 \\
PL4 & $\begin{array}{l}\text { Pratylenchus loosi isolate P11 28S } \\
\text { ribosomal RNA gene, partial sequence }\end{array}$ & $100 \%$ & $5 \mathrm{e}-143$ & $100 \%$ & EF446996.1 \\
PL5 & $\begin{array}{l}\text { Pratylenchus loosi isolate Jan-1 28S } \\
\text { ribosomal RNA gene, partial sequence }\end{array}$ & $99 \%$ & $2 \mathrm{e}-153$ & $96 \%$ & KF430797.1 \\
PL6 & $\begin{array}{l}\text { Pratylenchus loosi isolate EX11 28S } \\
\text { ribosomal RNA gene, partial sequence }\end{array}$ & $100 \%$ & 0.0 & $100 \%$ & KY424292.1 \\
\hline
\end{tabular}

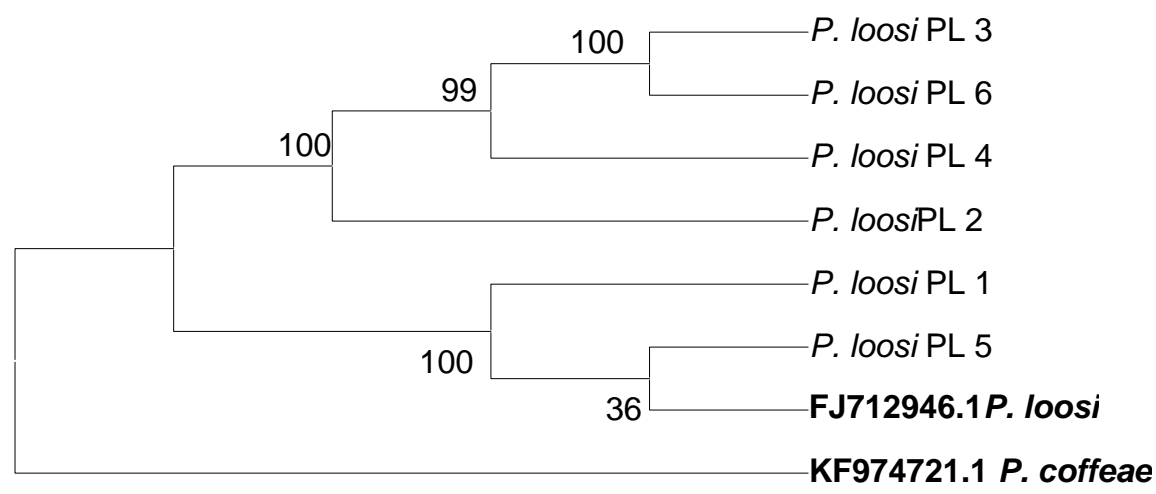

Figure 3: Maximum Parsimony tree of P. loosi populations (PL 1 - PL 6), other Pratylenchus populations obtained from GenBank based on the sequence alignment of the ITS region

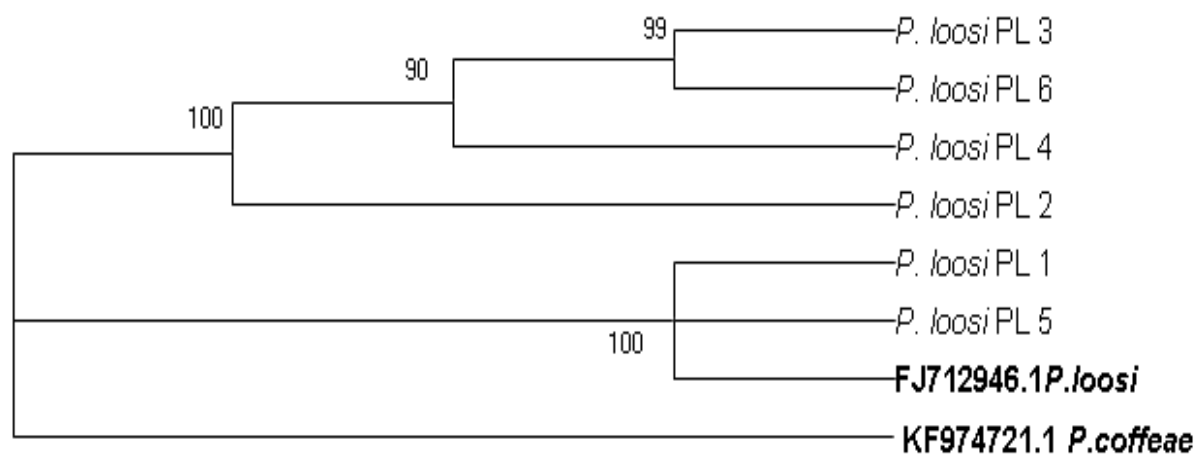

Figure 4: Neighbor Joining tree of $P$. loosi populations studied, other Pratylenchus populations obtained from GenBank based on the sequence alignment of the ITS region. 


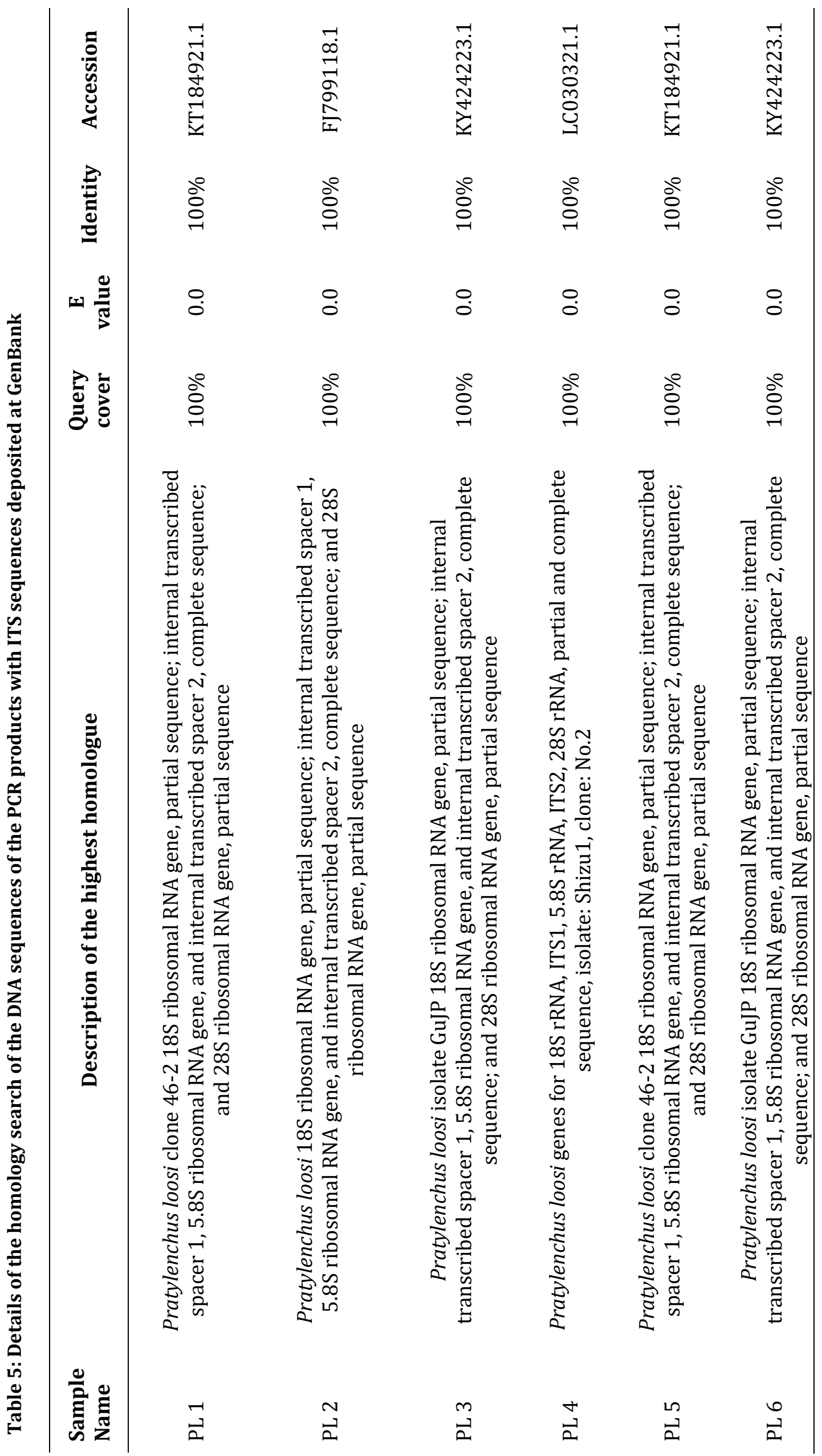




\section{CONCLUSIONS}

Overall results showed evidence of existence of morphotypes in the six P. loosi populations infesting tea in Sri Lanka. It also showed some divergence in the molecular data of the nematodes. Whether these divergence amount to differences in infestation patterns and severity and persistence of the nematodes in different regions of Sri Lanka with varied soil and environmental factors needs further investigation. Results of such investigations are important as they will indicate whether specific management strategies are required to control damage caused by the nematodes in each of the teagrowing areas in Sri Lanka.

\section{ACKNOWLEDGEMENTS}

Principle author is obliged to the Tea Research Institute of Sri Lanka and National Science Foundation of Sri Lanka for graciously providing financial support to carry out field and laboratory research in Sri Lanka and Australia without which this comprehensive study could not have been accomplished. Prof. Lalith Sooriyagoda of the University of Peradeniya is acknowledged for providing statistical guidance.

\section{REFERENCES}

Begum, F., Nyarko J. F., Sharma, S., Macleod, B., Collins, S. and Jones, M. G. K. (2019). Serendipitous identification of Pratylenchus curvicauda from the grainbelt of Western Australia. Journal of Nematology. Vol 51.

Castillo, P. and Vovlas, N. (2007). Pratylenchus, (Nematoda: Pratylenchidae): diagnosis, biology, pathogenicity and management. Nematology Monographs and Perspectives 6, 529 p.
De la Peña, E., Karssen, G. and Moens, M. (2007). Distribution and diversity of rootlesion nematodes (Pratylenchus spp.) associated with Ammophila arenaria in coastal dunes of Western Europe. Nematology.9, 881-901.

Duncan, L. W., Inserra, R. N., Thomas, W. K., Dunn, D., Mustika, I., Frisse, L. M., Mendes, M. L., Morris, K., and Kaplan, D. T. (1999). Molecular and morphological analysis of isolates of Pratylenchus coffeae and closely related species. Nematropica. 29, 61-80.

Finch TV 1.4.0 (Geospiza, Inc.; Seattle, WA, USA [on line]. Available at http://www. geospiza.com) [Accessed on 12.04.2019]

Gnanapragasam, N. C., and Mohotti, K. M. (2005). Nematode Parasites of Tea. In: Luc, M., Sikora, R. A. and Bridge, J. (ed). Plant Parasitic Nematodes in Sub Tropical and Tropical Agriculture. 581-593.

Handoo, Z. A., and Golden, M. (1989). A key and diagnostic compendium to the species of the genus Pratylenchus Filipjev, 1936 (lesion nematodes). Journal of Nematology. 21, 202218.

Handoo, Z. A., Carta, L. K., and Skantar, A. M. (2001). Morphological and molecular characterization of Pratylenchus arlingtoni n. sp., P. convallariae and P. fallax (Nematoda: Pratylenchidae). Nematology. 3, 607-618.

Inserra, R. N., Duncan, L. W., Vovlas N. and Loof, P. A. A. (1996). Pratylenchus loosi from pasture grasses in central Florida. Nematologica. 42, 159-172.

Inserra, R. N., Duncan, L. W., Troccoli, A., Dunn, D., Maia dos Santos, J., Kaplan, D. and Vovlas, N. (2001). Pratylenchus jaehni sp. n. from citrus in Brazil and its relationship with 
P. coffeae and P. loosi (Nematode: Pratylenchidae). Nematology. 3, 653-665.

Kumar, S., Stecher, G. and Tamura, K. (2016). MEGA 7: Molecular Evolutionary Genetics Analysis, Version 7.0 for bigger datasets. Molecular Biology and Evolution. 33, 18701874.

Loof, P. A. A. (1960). Taxonomic studies on the genus Pratylenchus (Nematoda). Tijdschrift voor Plantenziekten. 66,29-90.

Loof, P. A. A. (1991). The family Pratylenchidae Thorne, (1949). In: Manual of Agricultural Nematology (ed.). Nickle, W. R. and Dekker, M. Inc., New York, 363-394.

Marek, M., Zouhar, M., Douda, O., Manasova, M. and Rysanek, P. (2014). Exploitation of FTA cartridges for the sampling, long-term storage, and DNA-based analyses of plantparasitic nematodes. Phytopathology. 104, 306-312.

Mizukubo, T. (1998). Morphometric and molecular differentiation of Pratylenchus loosi (Nematode: Pratylenchidae) species complex from Japan and Sri Lanka. Proceedings of the $24^{\text {th }}$ International Nematology Symposium of European Society of Nematologists. 72.

Mizukubo, T., Orui, Y., Hanada, K. and Sano Z. (2003). Microevolutionary trend in Pratylenchus coffeae sensu stricto (Nematoda: Pratylenchidae): the diversity in PCR-RFLP phenotype, compatibility on host plants and reproductive segregation. Japanese Journal of Nematology. 3, 57-76.

Mohotti, K. M. (1998). Non-chemical approaches for management of root lesion nematode, Pratylenchus loosi Loof, 1960 in tea (Camellia sinensis (L.) O. Kuntz) with special reference to use of endospore-forming bacterium, Pasteuria penetrans. PhD Thesis, University of Reading, $289 \mathrm{p}$

Mohotti, K. M., Siddiqi, M. R., Bridge, J. and Gowen, S. R. (2002). Morphological and morphometric variations of Pratylenchus loosi sensu lato. Abstracts of Papers Presented at the Fourth International Congress of Nematology, 8-13 June 2002, Tenerife, Spain. Nematology 4, 305.

Orui, Y. (1996). Discrimination of the main Pratylenchus species (Nematoda: Pratylenchidae) in Japan by PCR-RFLP analysis. Applied Entomology and Zoology. 31, 505-514.

Román, J. and Hirschmann, H. (1969). Morphology and morphometrics of six species of Pratylenchus. Journal of Nematology. 1, 363-385.

Sambrook J., Fritsch E. F. and Maniatis, T. (1989). Composition of the electrophoresis buffer. In: Forsol, N., Nolan C., Ferguson M. and Ockler M. (eds). Molecular cloning, a laboratory manual. New York, USA, Cold Spring Harbor Laboratory Press.

Seinhorst, J. W. (1977). Pratylenchus loosi. CIH description of plant parasitic nematodes, Set 7, No.98, Commonwealth Institute of Helminthology, UK.

Siddiqi, M. R. (1986). Tylenchida, parasites of plants and insects. CAB International, UK, 645 pp.

Subbotin, S. A. and Moens, M. (2006). Molecular taxonomy and phylogeny. In: Perry, R. N., and Moens, M. (eds), Plant Nematology, CABI Publishing, Wallingford, UK, 33-58.

Uehara, T., Mizukubo, T., Kushida, A. and Momota, Y. (1998). Identification of 
Pratylenchus penetrans (Cobb) by PCR using ITS-based species-specific primers. Japanese Journal of Nematology. 28, 1-7.

Waeyenberge, L., Ryss, A., Moens, M., Pinochet, J. and Vrain, T. C. (2000).Molecular characterization of 18 Pratylenchus species using rDNA restriction fragment length polymorphism. Nematology. 2, 135-142.

Wu, H. Y., Tsay, T. T. and Lin, Y. Y. (2002). Identification and biological study of Pratylenchus spp. isolated from the crops in Taiwan. Plant Pathology Bulletin. 11, 123136. 